Proceedings

\title{
Criteria for the Selection of Working Fluids for Geothermal Power Plants: A Case Study in Spain †
}

\author{
Antonio Luis Marqués Sierra ${ }^{1, *}$ and Noe Anes Garcia ${ }^{2}$ \\ 1 Escuela de Ingeniería de Minas, Energía y Materiales, Universidad de Oviedo, Independencia, 13, \\ 33004 Oviedo, Spain \\ 2 ELMAC-Ingenieria, 33203 Gijón, Spain; noeanes@gmail.com \\ * Correspondence: marquesantonio@uniovi.es \\ + Presented at the 2nd International Research Conference on Sustainable Energy, Engineering, Materials and \\ Environment (IRCSEEME), Mieres, Spain, 25-27 July 2018.
}

Published: 26 November 2018

\begin{abstract}
An important key in binary geothermal power plant is the selection of working fluid. This design decision has great implications for the operation of this power plant. While there are many options available for working fluids, there are also many restrictions on the selection that relate to the thermodynamic properties of fluids, as well as considerations of salt, safety and environmental impact.
\end{abstract}

Keywords: organic rankine cycles (ORC); Spain; geothermal energy

\section{Introduction}

ORC cycles employ organic fluids, usually natural hydrocarbons or halogenated hydrocarbons. The choice of concrete working fluid will depend on the analyzable properties in its two-phase hood, and its operation under the conditions of the installation.

Given the wide spectrum of possible fluids, a series of criteria is followed according to the type of cycle that is expected to be obtained to find the most suitable one. A first criterion, common to all cases, is an environmental criterion: it is necessary to consider the current legislation that prohibits the use of certain refrigerants due to their capacity to destroy the ozone layer (CFCs and HCFCs). In addition, all those condensing at lower pressure than the atmospheric pressure will be discarded, to avoid requiring the incorporation into the cycle of a degasser, with the consequent simplification and cheapening of the installation.

For a subcritical cycle that is the case of this study, the ideal fluid will be that whose saturated steam line is parallel to the expansion line of the turbine, thus ensuring that it will work with maximum efficiency and always in the dry steam zone. If the two lines were convergent, there would be a risk of obtaining wet steam inside the turbine, having to resort to overheating in the boiler to try to avoid it. If on the contrary they were divergent, the temperature of the steam at the exit of the turbine would be too high, thus increasing the size, and therefore the cost, of the subsequent condenser.

Because of these requirements, the number of fluids to be used is reduced to the following: isobutane, n-butane, isopentane and n-pentane, trying in this work to expose the methodology used for the selection of an optimal working fluid for the previous design of the geothermal power plant. This work analyses a case study in northwestern Spain to select best working fluid for a ORC geothermal power plant. 


\section{Selection of Refrigeration Fluid}

In the industry there are two main technologies for cooling cold focus: with cooling tower and air condenser. The choice of one or the other will significantly influence the net power of the plant.

Climatic conditions and water availability are critical parameters that determine the choice between these two systems. Water cooling systems are generally considered less expensive in their construction and operation if water is available and cheap.

Although in some plants of arid zones using air-cooled can be more profitable, its energy capacity is highly dependent on climatic conditions and its net power output generally fluctuates between $20-25 \%$. In moderate climates, as study area, wet cooling towers are preferred, if the source of cooling water is available. With the use of a wet cooling tower, the working fluid can be cooled to a lower temperature, which improves cycle efficiency significantly. In the case of the binary plant under study there is availability of water in its location, therefore the wet cooling tower is chosen as the most suitable system.

To obtain the distribution of the wet temperature in the study area, the METEONORM application has been used, which contains a broad meteorological data base from any geographical point. The range of possible temperatures in the study area ranges from $-5^{\circ} \mathrm{C}$ to $25^{\circ} \mathrm{C}$, although the frequency of temperatures below $0^{\circ} \mathrm{C}$ is not usual, as it does not exceed $2 \%$. The graph clearly shows that the annual average wet temperature in the study area is $8^{\circ} \mathrm{C}$.

\section{Section (Heading 1)}

Configuration of the ORC has been showing in Figure 1. The ORC cycle of the modeled binary plant has four main elements: the heat exchanger with pre-heater and evaporator (point 6), the turbine with the generator (points 1-2), the condenser with the cooling tower (point 3 ) and the feed pump (points 4-5).

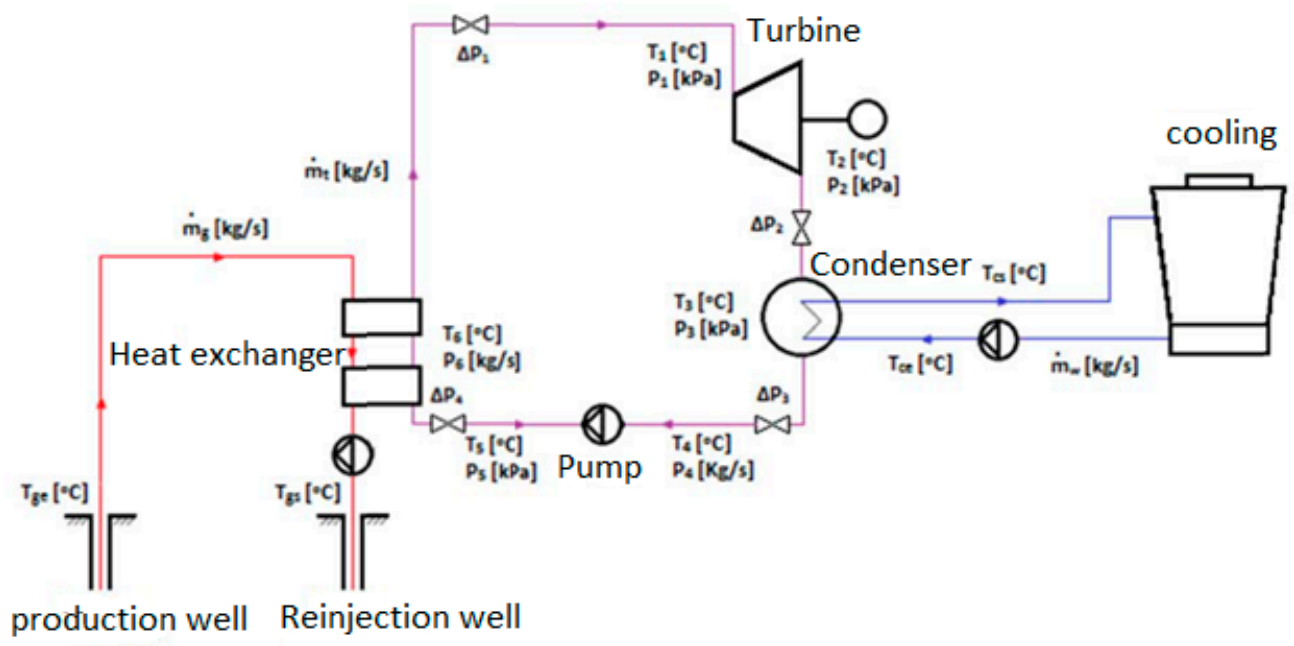

Figure 1. Outline of the ORC binary plant [1].

An important issue is the selection of working fluid. This design decision has great implications for the operation of a binary plant. While there are many options available for working fluids, there are also many restrictions on the selection that relate to the thermodynamic properties of fluids, as well as considerations of health, safety and environmental impact.

ORC cycles employ organic fluids, usually natural hydrocarbons or halogenated hydrocarbons. The choice of concrete working fluid will depend on the analyzable properties in its two-phase hood, and its operation in the conditions of the installation.

Given the wide spectrum of possible fluids, a series of criteria is followed according to the type of cycle that is expected to be obtained to find the most suitable one. A first criterion, common to all cases, is an environmental criterion: the current legislation prohibiting the use of certain refrigerants 
due to their capacity to destroy the ozone layer (CFCs and HCFCs) must be considered. Also, it is known that will discard all those that condense at a pressure lower than the atmospheric pressure, to avoid the incorporation of a degasser into the cycle, with the consequent simplification and cheapening of the installation.

For a subcritical cycle that is the case of this study, the ideal fluid will be that whose saturated steam line is parallel to the expansion line of the turbine, thus ensuring that it will work with maximum efficiency and always in the dry steam zone. If the two lines were convergent, there would be a risk of obtaining wet steam inside the turbine, having to resort to overheating in the boiler to try to avoid it. If on the contrary they were divergent, the temperature of the steam at the exit of the turbine would be too high, thus increasing the size, and therefore the cost, of the posterior condenser. As a result of these requirements, the number of fluids to be used is reduced to the following: isobutane, $\mathrm{n}$-butane, isopentane and n-pentane. The properties of the organic fluids are presented in Table 1.

Table 1. Thermodynamic properties of ORC fluids. [2].

\begin{tabular}{ccc}
\hline Working Fluid & Critical Temperature $\left({ }^{\circ} \mathbf{C}\right)$ & Critical Pressure $\mathbf{( k P a )}$ \\
\hline Isobutane & 13,592 & 3685 \\
n-Butane & 15,098 & 3718 \\
Isopentane & 1878 & 3409 \\
n-Pentane & 1939 & 3204 \\
\hline
\end{tabular}

The selection of working fluid among the four candidates is made using the criterion of maximum net power. For which a basic subcritical cycle has been programmed in EES (Engineering Equation Solver).

In the ORC optimization process, the pressure in the heat exchanger is chosen as the variable to maximize the net power. Bearing in mind that the design pressures do not exceed the industry's standard values. With the simulation in EES, the variation of the net power and the pressure of the heat exchanger as a function of the temperature of the geothermal fluid of the four working fluids.

\section{Conclusions}

Figure 2a shows that in the interval between $10-130{ }^{\circ} \mathrm{C}$ the four working fluids obtain similar net powers. From $130^{\circ} \mathrm{C}$, with isobutene a slightly higher net power is obtained compared to the rest of the working fluids.

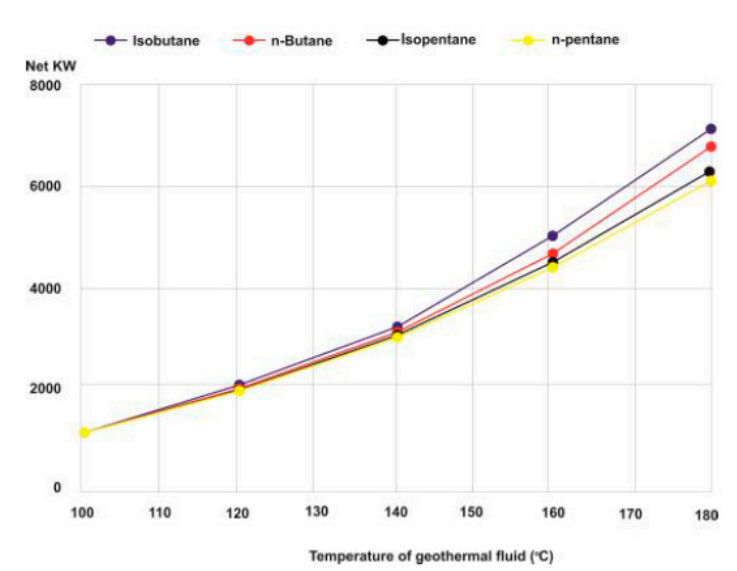

(a)

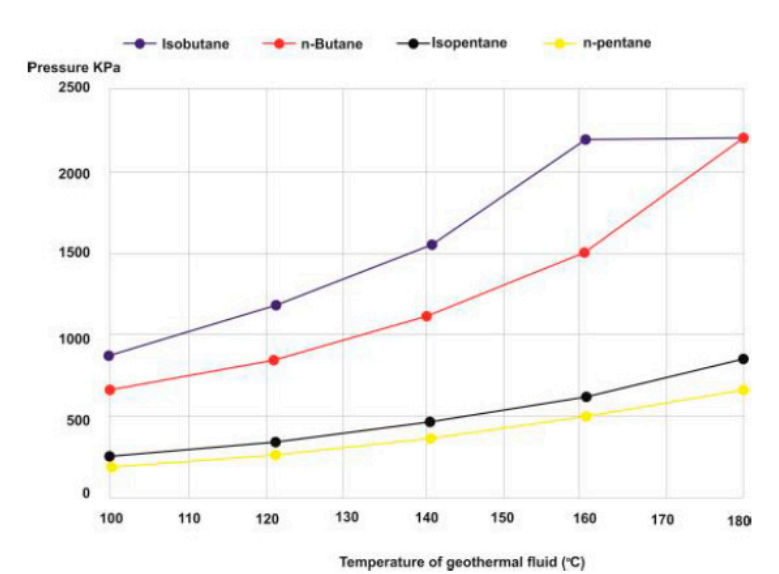

(b)

Figure 2. (a) Net power of the ORC according to the temperature of the geothermal fluid; (b) ORC pressure in Pre-heating-evaporator depending on the temperature of the geothermal fluid.

Figure $2 b$ shows the greater efficiency of isobutene in comparison with the rest of the working fluids. By operating with isobutane the geothermal resource is cooled more efficiently. Based on the 
above considerations, isobutane (R-600a) is the most suitable working fluid for the ORC cycle object of this study.

Methylpropane or isobutane is an organic compound belonging to the alkanes of formula $\mathrm{CH}_{3}-$ $\mathrm{CHCH}_{3}-\mathrm{CH}_{3}$, isomer of butane. In its diagram T-s it is seen that it is a suitable fluid for a subcritical cycle since its critical point is for a temperature of $134.7^{\circ} \mathrm{C}$.

Conflicts of Interest: The authors declare no conflict of interest.

\section{References}

1. Marques, A.L. Diseño de una Planta Geotermica Binaria en el Noroeste de España. Master's Thesis, Engineering Geology-University of Oviedo, Oviedo, Spain, 2014.

2. DiPippo, R. Geothermal Power Plants: Principles, Applications and Case Studies, 4th ed.; ButterworthHeinemann: Oxford, UK, 2005; pp. 254-296.

(C) 2018 by the authors. Licensee MDPI, Basel, Switzerland. This article is an open access article distributed under the terms and conditions of the Creative Commons Attribution (CC BY) license (http://creativecommons.org/licenses/by/4.0/). 